\title{
Quasi-biennial and quasi-triennial oscillations in geomagnetic activity indices
}

\author{
R. P. Kane \\ Instituto Nacional de Pesquisas Espacias - INPE, Caixa Postal 515, 12201-970 - São José dos Campos, SP, Brasil
}

Received: 10 December 1996 / Revised: 7 May 1997 / Accepted: 9 June 1997

\begin{abstract}
Data for geomagnetic activity index aa for 1868-1994 were subjected to spectral analysis for 12 intervals each of 11 consecutive years. In each interval, QBO and QTO (quasi-biennial and quasi-triennial oscillations) were observed at $\sim 2.00,2.15,2.40,2.70 \mathrm{y}$ and $\sim 3.20,3.40 \mathrm{y}$, but not all in all intervals. These fluctuations are absent near (2-3 y before and after) the sunspot minima and are present only as 2 or 3 peaks in aa indices, one near or before the sunspot maximum and the other (one or two, generally the larger ones) in the declining phase of the sunspot cycle. Comparison with the solar wind (1965 onwards) showed a fairly good match, indicating that the aa variations were mostly due to similar variations in the solar wind, which must have their origin in solar physical processes. A few aa variations did not match with solar wind. When compared with terrestrial phenomena, no match was found with stratospheric low-latitude zonal wind QBO; but some QTO in a matched QTO in ENSO (El Nino/ Southern Oscillation). This may or may not be a chance coincidence and needs further exploration.
\end{abstract}

\section{Introduction}

After the initial work of Bartels (1963) discussing the time variation of geomagnetic activity indices $\mathrm{Kp}$ and Ap for 1932-1961, Fraser-Smith (1972) made an FFT analysis of 38 y (1932-1969) of Ap data and obtained very promonent peaks at $35.6,16.1,10.2,0.5 \mathrm{y}$, prominent peaks at 7.04, 5.14, 4.10, 1.47, 1.09 y and 27.2, 27.6 days, moderate peaks at 54.0, 37.4, 30.5, 26.9, 18.7, 14.1, $13.7,13.6,9.39$ days and very weak peaks for $2-9$ days. When Mayaud (1973) produced an homogeneous series of aa indices beginning in 1868, Delouis and Mayaud (1975) conducted a spectral analysis for the $103 \mathrm{y}$ series and obtained results identical to those of Fraser-Smith (1972) for the common period 1932-1969. For astronomical (or modulation) lines, e.g., diurnal, seasonal, they found stability, while for astrophysical (or excitation) lines, e.g., the 11-y solar cycle or the 27-day solar rotation period, there was more or less stability. Feynman (1982) compared aa index variations with sunspot numbers and, since the solar wind drives the geomagnetic activity, he concluded that the 11-y solar cycle as represented by the sunspot numbers was very different from the 11-y cycle of the solar wind and geomagnetics. The solar wind (or aa indices) cycle could be decomposed into a $\mathrm{R}$ component with the phase and amplitude of the sunspot cycle and, an I component almost $180^{\circ}$ out of phase with the $\mathrm{R}$ component. The $\mathrm{R}$ component would be due to sporadic or short-lived solar events, while the I component would be due to longlived solar features such as coronal holes. Legrand and Simon (1989) discussed the contribution to geomagnetic activity of shock waves and of the solar wind, while Gonzalez et al. (1990) emphasized the role of the dual peak cycle distribution of intense geomagnetic storms.

In an earlier paper (Kane, 1986), spectra of several geomagnetic indices (Ap, AN, AS, AE, AU, AL, Dst) were examined and periodicities from 2 days to several years were obtained, many of which were common to all indices. In some cases, some differences were observed. Now, data for aa indices are available for more than $125 \mathrm{y}$. In this study, a spectral analysis is conducted by the sophisticated method of maximum entropy spectral analysis and the results are compared for successive time intervals, to check the stability of the various periodicities in general and of QBO and QTO (quasi-biennial and quasi-triennial oscillations) in particular.

\section{Method of analysis}

Maximum entropy spectral analysis (MESA, Burg, 1967; Ulrych and Bishop, 1975) is much more accurate than the conventional BT (Blackman and Tukey, 1958) method. In BT, only certain frequencies $(f / 2 \mathrm{~m})$ can be studied, where $f=1,2, \ldots \mathrm{m}$, where $\mathrm{m}$ is the lag, usually recommended to be $\sim 25 \%$ of the data length. In MESA, any frequency between 0 and 0.5 (folding 
frequency) can be studied, with spacings (steps) as small as desired. In MESA, there is a parameter LPEF (length of the prediction error filter) which can be chosen. For low LPEF, only low periodicities are revealed. For larger LPEF, larger periodicities are revealed, as large as even data length; but then, low periodicities show peaksplitting. Experiments with artificial samples (Chen and Stegen, 1974; Kane, 1977, 1979; Kane and Trivedi, 1982) illustrate the high accuracy of MESA in the low periodicity region. In the region of large periodicities, the errors can be $\sim 10 \%$ or more (e.g., $80 \pm 8$ in a sample of 100 data points). Experience shows that an LPEF of $50 \%$ of the data length is generally adequate, and is used in the present analysis.

MESA has a major drawback viz., the power estimates are not reliable (input signals of similar amplitudes showed different powers). Lacoss (1971) mentions that in MESA, the heights of the output peaks are expected to be proportional to the square of the power of the signal, while the area under the peak is expected to be proportional to the power of the signal. But this expectation is not always fulfilled (see Kane and Trivedi, 1982). Hence, an alternative approach was adopted, viz., MESA was used only for locating possible peaks $T_{k}(k=1$ to $n)$ and these $T_{k}$ were then used in the expression:

$$
\begin{aligned}
f(t) & =A_{o}+\sum_{k=1}^{n}\left[a_{k} \sin \left(2 \pi t / T_{k}\right)+b_{k} \cos \left(2 \pi t / T_{k}\right)\right]+E \\
& =A_{o}+\sum_{k=1}^{n} r_{k} \sin \left(2 \pi t / T_{k}+\phi_{k}\right)+E
\end{aligned}
$$

where $f(t)$ is the observed time series and $E$ the error factor. A multiple regression analysis (MRA, Bevington, 1969) was then carried out to get the best estimates of $A_{o},\left(a_{k}, b_{k}\right)$ and their standard errors by a least-square fit. From these, $r_{k}$ and their standard errors $\sigma_{r}$ (common for all $r_{k}$ in this methodology) can be calculated. Any $r_{k}$ exceeding $2 \sigma_{r}$ would be considered as significant at a $95 \%$ (a priori) confidence level.

\section{Sample analysis}

Data for Ap, aa indices and sunspot numbers were obtained from Mayaud (1973), McKinnon (1987) and Solar Geophysical Data, Prompt Reports, issued by National Geophysical and Solar-Terrestrial Data Center, Boulder, Colorado, USA.

Figure 1 (left half) is a sample plot of aa indices for the recent decade 1984-1994. Figure 1a shows the aa monthly means, which show considerable variation from month to month. Figure $1 \mathrm{~b}$ shows 3-monthly aa running means. Some periodic structures are seen. The thick line plot in-between is for 12-monthly means (centered three months apart) of sunspot number. Figure 1c shows aa 12-monthly running means. Figure 1d shows every third value of the same 12-monthly running means of aa i.e., only four (seasonal) values per year. Figure 1e,f shows 3-year and 4-year running means of aa. (These should be for 12 and 16 seasons; but, for matching of centering with 12-monthly means, 13 and 17 seasons i.e., 39 and 51 months were used). Figure 1g,h shows the differences between the 12-monthly aa means and the 3-yearly and 4-yearly aa means, designated as aa (12-39) and aa (12-51) respectively. Since aa indices are expected to have two components, one of which, the R component, is directly proportional to sunspots, a regression analysis was carried out between 12-monthly running means of aa index and sunspot numbers. The correlation coefficient was +0.60 and the regression equation was $a(R)=14.84+0.08 \mathrm{R}$. Feynman (1982) used a slightly different method which yielded $\mathrm{aa}(\mathrm{R})=5.38+0.12 \mathrm{R}$. These regression equations were used to obtain the "expected" values of aa and these were subtracted from the original aa series and the residues aa(I) were considered as the I component, shown in Fig. 1i, for our regression equation.

Every series of Fig. 1 (left half) was subjected to spectral analysis (MESA) and the possible peaks $T_{k}$ for every series were used in Eq. (1) to obtain their amplitudes (by MRA), shown in the right half of Fig. 1. Thus, Fig. 1a (right half) refers to spectra of the monthly mean series and shows peaks at $0.22 \mathrm{y}$ ( $\sim 2.6$ months $), 0.51$ y $(\sim 6 \mathrm{~m}), 0.73$ y $(\sim 9 \mathrm{~m}), 0.80 \mathrm{y}$ $(\sim 10 \mathrm{~m}), 1.07 \mathrm{y}(\sim 13 \mathrm{~m})$. The hatched portion represents the $2 \sigma$ limit. Whereas the semi-annual variation is prominent, the annual variation is not very prominent, at least in this sample. Later, a peak at $1.30 \mathrm{y}$ is very prominent and could be compared with a similar peak in solar wind measured by satellites in recent decades (Richardson et al., 1994; Gazis et al., 1995) and in the north-south component $B_{z}$ of IMF (Szabo et al., 1995; Paularena et al., 1995). There is a peak at $1.91 \mathrm{y}(23 \mathrm{~m})$ and another at $2.85 \mathrm{y}(34 \mathrm{~m})$, both in the QBO region and finally, the strongest peak at $10.2 \mathrm{y}$. Figure $1 \mathrm{~b}$ (right half) shows the spectra for 3-monthly means. Except for the 0.22 y peak which has disappeared, all other peaks are identical to Fig. 1a. When 12-monthly means are analyzed (Fig. 1c, right half), all the seasonal peaks disappear, the 1.30 y peak, besides being reduced in size, appears as $1.36 \mathrm{y}$, two peaks appear at 1.98 and $2.95 \mathrm{y}$ and the strongest peak appears at $9.8 \mathrm{y}$. A spectral analysis of the sunspot numbers for the same interval showed peaks marked by full circles in Fig. 1b (right half) where the size of the circle roughly represents the strength of the peak. The largest peak at $9.4 \mathrm{y}$ tallies with the $9.8 \mathrm{y}$ peak of aa, and the 2.95 and $2.27 \mathrm{y}$ sunspot peaks tally (only roughly) with 2.77 and $1.91 \mathrm{y}$ of aa. When only 4 (seasonal) values per year of the 12monthly running means are analyzed, (Fig. 1d, right half), the peaks are almost the same as those of Fig. 1c (right half).

Figure 1e,f (right half) show spectra for the 3-y and 4-y running means of aa. Here, all low periodicities are almost wiped out and only one prominent peak remains at $\sim 8.0 \mathrm{y}$, not at $10.0 \mathrm{y}$, indicating that some distortion of solar cycle can occur. When the 3-yearly and 4-yearly means are subtracted from the 12-monthly means, the residues aa (12-39) and aa (12-51) show spectra as shown in Fig. 1g,h (right half). Compared to Fig. 1c,d (right half) for the 12-monthly means, these residues still 


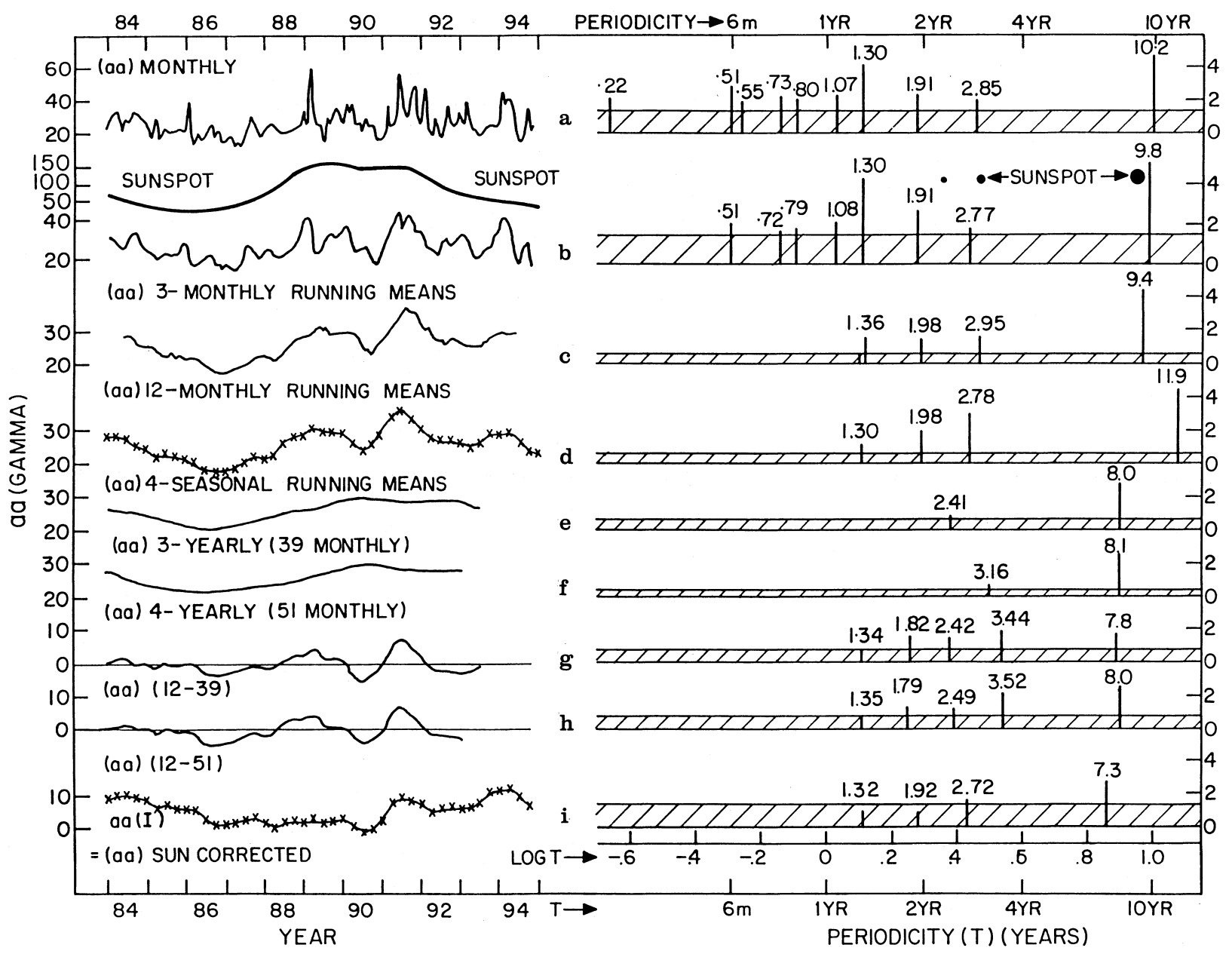

Fig. 1a-i. Left half, plots of aa indices; right half, spectra. a Monthly means of aa index; b 3-monthly running means of aa and the smoothed sunspot numbers (thick line); c 12-monthly running means; d 4 seasonal running means (4 values per year); e 3-yearly (39 months)

show a barely significant peak at $\sim 1.35 \mathrm{y}$ and a significant peak at $\sim 1.80 \mathrm{y}$; but the single peak at $(2.78-2.95)$ y has split into two distinct peaks at $\sim 2.45 \mathrm{y}$ and $\sim 3.50 \mathrm{y}$, i.e. a QBO and a QTO. Finally, the sunspot-corrected aa i.e., its I component (Fig. li, right half) shows a barely significant peak at $\sim 2.70 \mathrm{y}$. Incidentally, Fig. 1e,f,g,h,i (right half) shows a small peak at $\sim(7-8)$ y very unlike the major sunspot peak at $\sim 10 \mathrm{y}$ and could be of some other origin.

\section{Results for longer series}

Geomagnetic indices generally have strong semi-annual and annual variations. Basically, two mechanisms are proposed as possible explanations viz., axial mechanism related to the heliolatitude excursion of the Earth $\left(+7.2^{\circ}\right.$ to $-7.2^{\circ}$ ) and the other to the orientation of the Earth's magnetic dipole relative to the Earth-Sun line (Gonzalez et al., 1993 and references therein). However, the detailed analysis of Gonzalez et al. (1993) indicates multiple origins for these variations and, since the interest of the present study is in QBO and QTO, the running means (4 values per year); $\mathbf{f}$ 4-yearly (51 months) running means (4 values per year); $\mathbf{g}$ aa (12-39) i.e., $\mathbf{c}$ minus $\mathbf{e} ; \mathbf{h}$ aa (12-51) i.e., c minus f; i aa(I) i.e., sunspot-corrected aa. For spectra in the right half, the hatched portion in the $2 \sigma$ limit

seasonal variations are eliminated by calculating the 12monthly running means. As shown in Fig. 1, this procedure does not cause any distortion of QBO and QTO. In what follows, only the analysis of the 12monthly means is mostly presented.

Feynman (1982) mentions that the I component minima occur close to the sunspot maxima. To examine this in detail, Fig. 2 shows the plots for each solar cycle separately. The thin line plots (R) are for sunspot numbers and also represent the $\mathrm{R}$ component of aa indices. The thick line represents the I component of aa indices, obtained as aa $(\mathrm{I})=\mathrm{aa}-\mathrm{aa}(\mathrm{R})$, where $\mathrm{aa}(\mathrm{R})$ was obtained by using our regression equation $a a(R)$ $=14.84+0.08 \mathrm{R}$, and the crosses show the aa(I) by using Feynman's equation aa $(\mathrm{R})=5.38+0.12 \mathrm{R}$ and, except for a slight overall shift in values, the thick line fluctuations are similar to those of the crosses. The aa(I), both thick line and crosses, show patterns differing largely from cycle to cycle. Feynman (1982) had noted this and mentioned that whereas in the twentieth century (especially since 1932) aa(I) showed a minimum close to the sunspot maximum and a maximum shortly before the sunspot minimum, the data for the pre-1900 


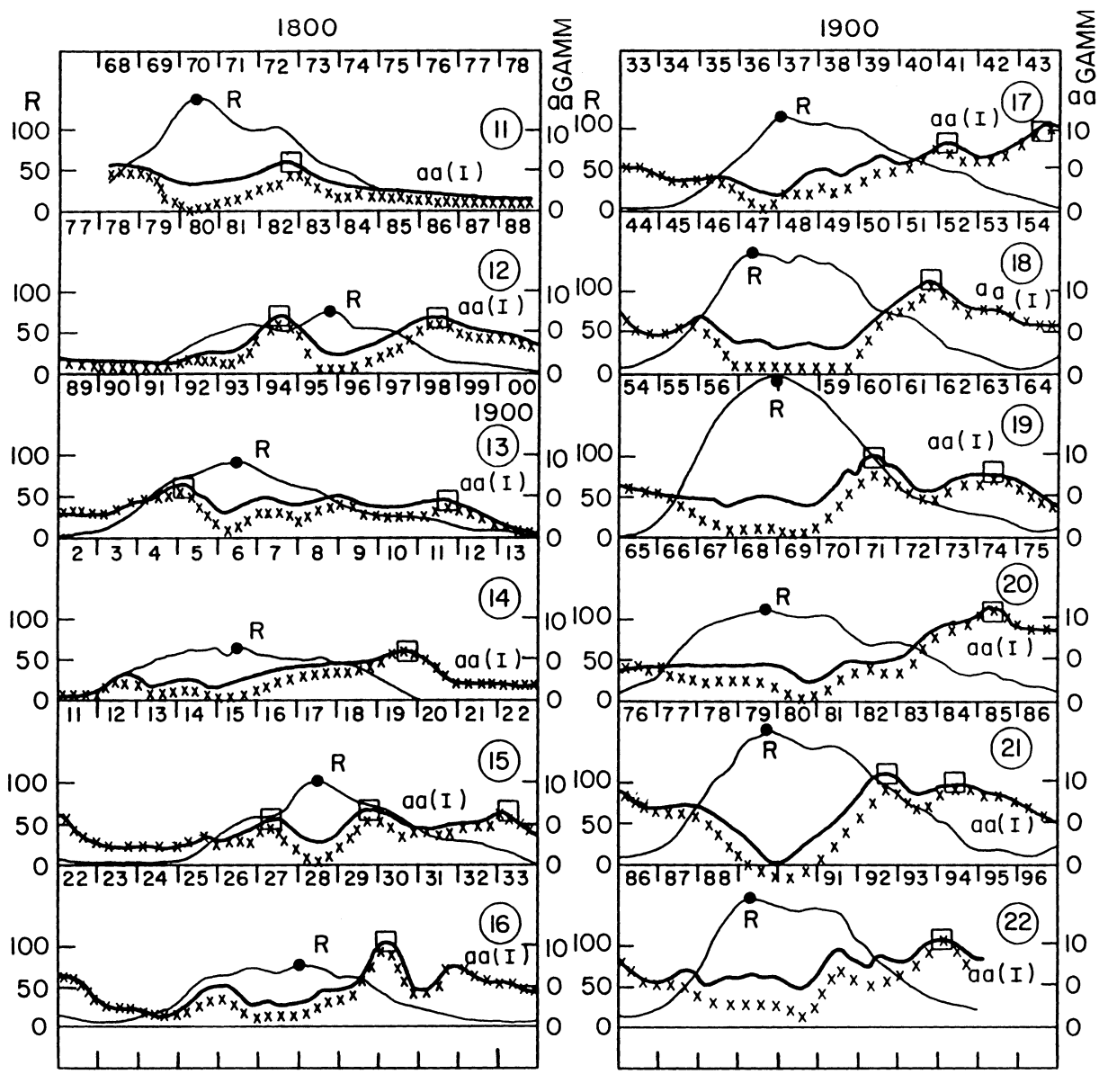

Fig. 2. Sunspot numbers $\mathrm{R}$ (thin lines) and aa(I) obtained by using direct regression with sunspots (thick line) and using Feynman's regression (crosses), separately for each sunspot cycle (1122)

\section{YEAR}

era were not well ordered. In our Fig. 2, the difference in behaviour between cycles (11-16) and (17-22) is seen; but in each of these two groups, the patterns are by no means uniform. Hence, a spectrum analysis seemed to be warranted.

Figure 3 shows the spectra for the aa index series of various lengths. The top plot Fig. 3a shows spectra for aa indices for $127 \mathrm{y}$ between 1868-1994, using only annual means (one value per year). The hatched portion shows the $2 \sigma$ limit. Periodicities in the QBO and QTO region are all insignificant and, the first significant low periodicity is $5.4 \mathrm{y}$, followed by $8.1,9.7,10.8$ (strongest), 12.6, 22.4 and $33.2 \mathrm{y}$. For the same period, sunspots (annual values) showed 8.2, 9.6, 10.6 (strongest), 12.6 and $36.1 \mathrm{y}$. These are shown as solid circles, with sizes roughly proportional to their amplitudes. (The open circles indicate small peaks of borderline significance). As can be seen, except for 5.4 (sunspots had 5.7) and 22.4 (sunspots had 18.8) y, all aa index peaks had similar peaks to the sunspot numbers. Thus, in these data series of several decades, the geomagnetic activity seems to be completely controlled by solar activity. It is interesting to note that the aa index shows a 33.2 y peak while sunspots show $36.1 \mathrm{y}$. In a sample of 127 yearly values, MESA gives periods near $30 \mathrm{y}(25 \%$ of data length) with an accuracy of $0.5 \mathrm{y}$. Hence, this difference is significant. The lack of significance for QBO and QTO could be either because these are basically insignificant or have characteristics varying with time.

The next two plots (Fig. 3b,c) are for the two successive 63-y intervals between 1869-1931 and 19321994. In both, QBO and QTO are still insignificant and significant periodicities appear from $\sim 3.5 \mathrm{y}$ onwards. In the earlier part (1869-1931), aa has significant peaks at 3.9 and $4.4 \mathrm{y}$; but sunspots have barely significant peaks (open circles) in this region. On the other hand, sunspots have a very strong peak at 11.6 years (matching $11.9 \mathrm{y}$ of aa), a peak at $5.8 \mathrm{y}$ (matching $5.7 \mathrm{y}$ of aa), a peak at $8.3 \mathrm{y}$ (no match in aa), and a peak at $23.4 \mathrm{y}$ (very roughly matching 25.6 y of aa). In the latter part (19321994), the matching is better. For this interval, data are available for the Ap index also (Solar Geophysical Data) and the Ap spectra are shown by solid triangles. Almost every peak of aa is seen in Ap also, even the insignificant ones in the QBO and QTO region. The sunspots also have similar peaks, indicating almost complete control over geomagnetic activity. The large periodicity was $31.1 \mathrm{y}$ for Ap (varying from the $35.6 \mathrm{y}$ mentioned by Fraser-Smith, 1972, probably because of our 63 y data against 38 y data used by Fraser-Smith), 29.2 y for sunspots and 29.1 y for aa index.

Figure 3d,e,f shows aa spectra for the consecutive 42$y$ intervals 1869-1910, 1911-1952 and 1953-1994. The QBO and QTO are now significant, 2.68 and $2.63 \mathrm{y}$ in 


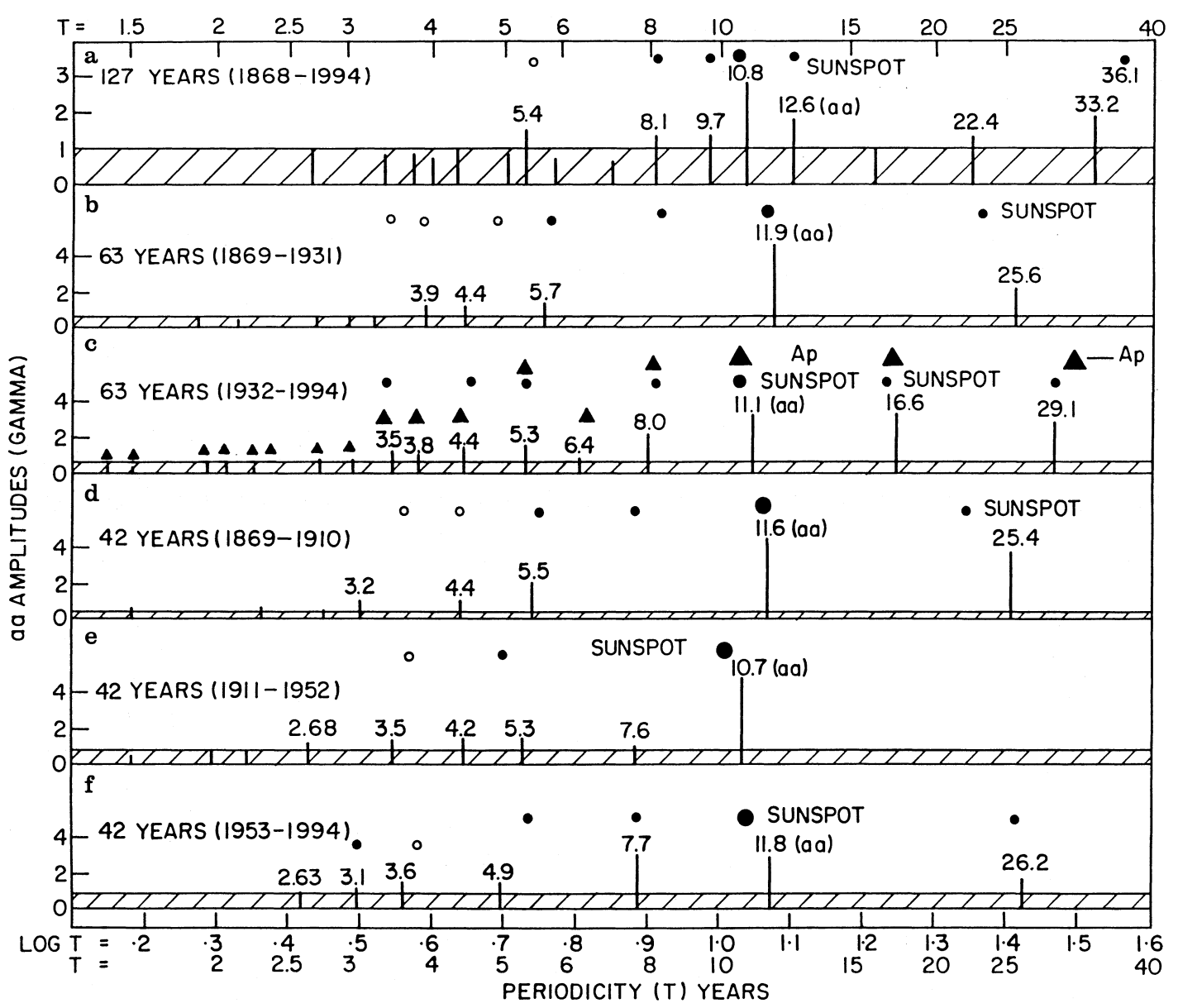

Fig. 3a-f. Spectra for aa series of various lengths, a 1868-1994, 127 y, b, c 1869-1931 and 1932-1994, 63 y each, d,e,f 1869-1910, 1911-1952, 1953-1994, 42 y each. Solid and open circles show significant and

Fig. 3e,f and 3.2, 3.5, (3.1, 3.6) years in Fig. 3d,e,f. Later, $\sim 4.3$ and $\sim 5.4$ y appear in Fig. 3d, e while 4.9 y appears only in Fig. 3f. A peak at $7.6 \mathrm{y}$ appears in Fig. 3e,f but not in Fig. 3d. All three Fig. 3d,e,f show prominent solar cycle peaks $(11.6,10.7,11.8 \mathrm{y})$. A peak near $25 \mathrm{y}$ appears in Fig. 3d,f but not in Fig. 3e. Thus, considerable variations occur in these consecutive 42-y intervals. Hence, analysis was carried out for still finer intervals of $21 \mathrm{y}$ each, and the results are shown in Fig. 4.

Figure $4 \mathrm{a}$ refers to $1869-1889$, the earliest $21 \mathrm{y}$, and shows 3.21 and 4.80 y periodicities significant and $11.9 \mathrm{y}$ very prominent. In the next $21 \mathrm{y}$, (1890-1910, Fig. 4b), several other periodicities appear and the aa solar cycle peak is at $13.8 \mathrm{y}$. During this interval, the sunspots had a 12.6 y peak and a smaller 5.7 y peak, almost matching with the 6.0 y peak of the aa index. There were sunspot peaks at 2.34 and $2.92 \mathrm{y}$ also but significant at a $1 \sigma$ level only. Thus, the aa peaks at $1.87,2.37,3.10,4.23 \mathrm{y}$ during 1890-1910 should have a non-solar origin.

Figure $4 \mathrm{c}$ refers to the $21 \mathrm{y}, 1911-1931$. Here, only $3.48,4.75$ and 11.3 y appear significantly in the aa index and only $11.3 \mathrm{y}$ matches roughly with $10.3 \mathrm{y}$ of sunspots, while $4.75 \mathrm{y}$ of aa is different from $4.28 \mathrm{y}$ of sunspots. Figure $4 \mathrm{~d}$ for the 21 y $1932-1952$ shows the barely significant peaks for sunspots and solid triangles for Ap index. Hatched portions show the $2 \sigma$ limits

strongest aa peak at $10.3 \mathrm{y}$, matching very well with 10.4 y peak of sunspots; but Ap has a peak at $8.8 \mathrm{y}$. Both aa and Ap have peaks at 2.64 and $4.18 \mathrm{y}$, with no corresponding peaks in sunspots.

Figure $4 \mathrm{e}$ for the 21 y $1953-1973$ shows a peak at $3.48 \mathrm{y}$ in aa and Ap but not in sunspots. A peak at $4.80 \mathrm{y}$ appears in aa but not in Ap, indicating that aa and Ap are not always alike. The solar cycle peak is at $11.1 \mathrm{y}$ for aa (matching very well with $11.2 \mathrm{y}$ for sunspots) and at $10.6 \mathrm{y}$ for Ap, again indicating a slight difference between aa and Ap. Incidentally, the 3.48 and 4.80 y peaks of aa for this interval are seen in an earlier interval also (3.48 and $4.75 \mathrm{y}$ in Fig. 4c). Figure $4 \mathrm{f}$ for the recent 21 y 1974-1994 shows a 10.0 y peak for sunspots, but 7.93 y for aa and 8.25 y for Ap. Peaks at $2.39,3.40$ and 5.39 y seem to have matching peaks (2.39, $3.24,5.02 \mathrm{y}$ ) in sunspots in this interval. Thus, at least in some intervals, even sunspots may have significant QBO and QTO, which may get reflected in aa and Ap.

Figure 5 shows the spectra for aa(I) (the thick lines of Fig. 2) as also for the residue aa (12-39) illustrated in Fig. 1g. Comparing Fig. 5a for the 21 y 1869-1889 with Fig. 4a for the aa index for the same interval, periodicities near $3.25 \mathrm{y}(\mathrm{QTO})$ and $4.75 \mathrm{y}$ are prominent in aa, aa(I) and aa (12-39), while $1.94 \mathrm{y}(23 \mathrm{~m})$ and $2.49 \mathrm{y}$ 


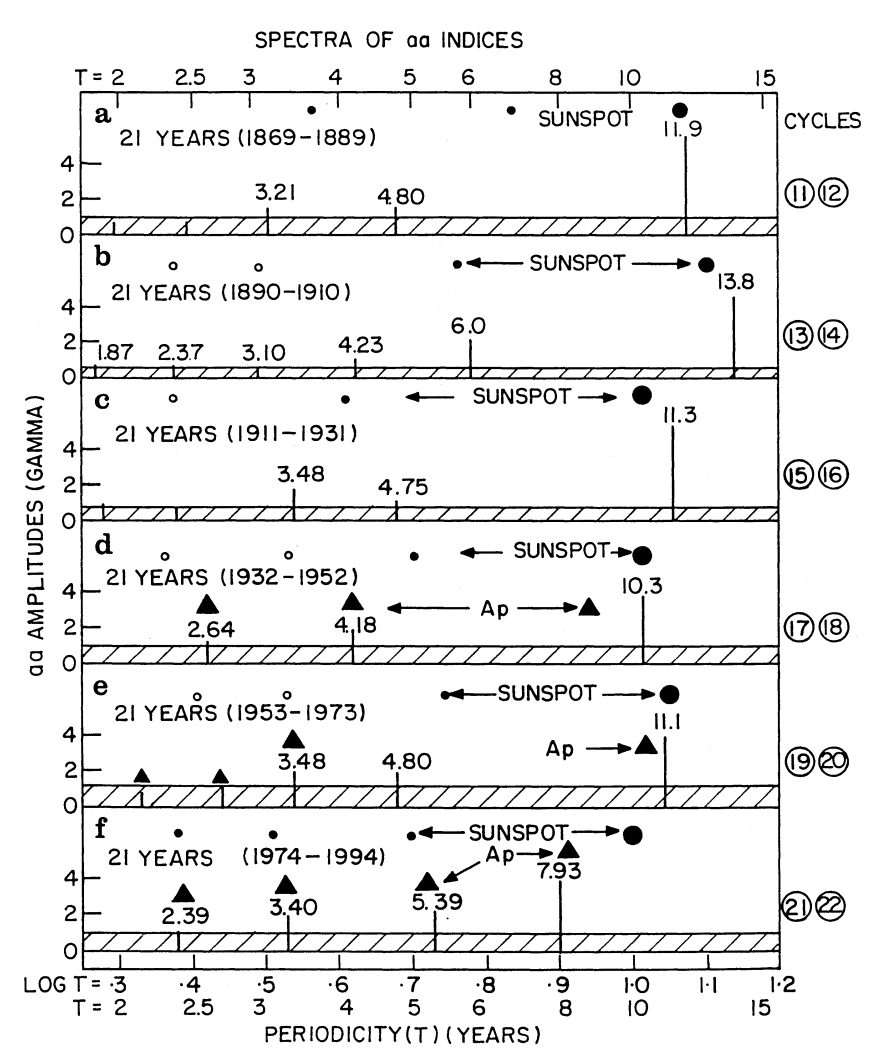

Fig. 4a-f. Spectra for aa series for 1869-1889, 1890-1910, 1911-1931, 1932-1952, 1953-1973, 1974-1994, 21 y each. Solid and open circles show peaks for sunspots and solid triangles for Ap index

$(30 \mathrm{~m})$ are seen significantly in aa $(12-39)$ but insignificantly in aa and aa(I). Comparing Figs. $5 \mathrm{~b}$ and $4 \mathrm{~b}$ for 1890-1910, 2.37 years $(28 \mathrm{~m})$ and $3.14 \mathrm{y}(38 \mathrm{~m})$ are significant in both aa(I) and aa (12-39), but not in aa and 1.87 years $(22 \mathrm{~m})$ and 4.15 years $(50 \mathrm{~m})$ are significant in aa and aa (12-39) but only marginally significant in aa(I). A peak near $6.4 \mathrm{y}$ is also significant in all. In Figs. 5c and 4c for 1911-1931, peaks at $\sim 1.90$, $2.35,2.85,3.50$ and $5.0 \mathrm{y}$ are significant in both aa(I) and aa (12-39); but aa shows only 3.48 and 4.75 y. A strong peak near $11 \mathrm{y}$ appears in aa and aa(I) only. In Fig. 5d for 1932-1952, peaks at $\sim 2.00,2.69$ and $3.75 \mathrm{y}$ are significant for aa(I) and aa (12-39) and aa(I) shows a strong 11-y cycle; but all these are different from Fig. 4d. In Fig. 5e for 1953-1973, periodicities $\sim 2.15$, $2.75,3.50$ appear, as also a strong solar cycle peak in aa(I), similar to that for aa in Fig. 4e. Finally, in Fig. 5f for 1974-1994, peaks appear at $\sim 2.30,3.43$ and $5.30 \mathrm{y}$, similar to those in Fig. 4f and aa(I) shows a prominent peak near $9.0 \mathrm{y}$. Thus, in all these 21 -y intervals, QBO near 2.00, 2.15, 2.40, $2.70 \mathrm{y}$ and/or QTO near 3.20, 3.40, $3.60 \mathrm{y}$ and/or higher periodicities $(\sim 4.2,4.4,4.6,4.8$, $5.2 \mathrm{y})$ are seen. In addition, aa(I) shows strong solar cycles since 1911 until present-day in agreement with the findings of Feynman (1982).

Since MESA gives very accurate results in the QBO and QTO region (for a data sample of 20 or more years), these results cannot be dubbed as random. Instead, genuinely different characteristics in different intervals are indicated. Figure 6 shows spectra of 3-monthly aa indices (44 values in 11 years) for each sunspot cycle number 11-22 separately. As can be seen, whereas most of the low periodicities are insignificant, some QBO and/ or QTO peaks (and also a peak near $1.4 \mathrm{y}$ ) are significant in some cycles.

\section{Relationship with solar wind}

Periodicities in geomagnetic indices in the QBO, QTO and nearby regions have been reported earlier. FraserSmith (1972) and Delouis and Mayaud (1975) mentioned peaks at 7.0, 5.1 and 4.1 y. Currie (1976) mentioned peaks at 3, 4 and 7 y. Kane (1986) reported peaks at 2.0, 2.7, 4, 5 and $7 \mathrm{y}$. Gonzalez et al. (1993) reported broad peaks near 2.9 and 4.4 y. However, these average values cannot be very meaningful, as the characteristics seem to change drastically (both qualitatively and quantitatively) from one solar cycle to another. From a study of geomagnetic storms, Gonzalez et al. (1990) showed that the yearly distribution of intense storms had two peaks around the solar maximum, one at the solar maximum or slightly earlier and the other in the early part of the descending phase, with an average separation of 3-4 y. Gonzalez et al. (1993) extended the analysis to moderate storms also and came to the same conclusion. Thus, the 3-4 y periodicities would be due to this dual-peak distribution structure and could be related to a similar dual-peak structure present in the intensity of certain coronal processes, as shown earlier by Gnevyshev (1967). Recently, Gonzalez et al. (1996) showed that low-latitude coronal holes also had a dual peak distribution, with the peaks corresponding to those of geomagnetic storms. However, as seen from Fig. 2, whereas the first peak of aa indices (marked by squares) does occur at or before the sunspot maximum (within 0-2 y), the second aa peak may be anywhere within 2-6 y after the sunspot maximum, and often, there are more than two aa peaks. It is this complexity that results not only in the 3-4 y periodicities but also periodicities in the QBO (2-3 y) region in some cycles. Gonzalez and Gonzalez (1987) detected peaks at 1.5 and $3.7 \mathrm{y}$ in the polarity of IMF. It is likely that these features creep in the aa and Ap indices. Rogova and Shatashvili (1990) reported quasi-periodic 2-y variations in cosmic rays, solar activity, solar wind and geomagnetic activity. Sugiura and Poros (1977) and Rangarajan (1985) reported a quasi-biennial oscillation in geomagnetic disturbance field. Solar wind data are available from 1962, but more regular information dates from 1965 (Gosling et al., 1976). Recently, Gazis et al. (1995) presented a study of the long-term periodicities in solar wind velocity during the last three solar cycles, mainly confirming the presence of a 1.3 -y periodicity in the recent solar cycle 22, earlier reported by Richardson et al. (1994). Data for solar wind were obtained from these publications. Figure $7 \mathrm{a}$ (thin line) shows a plot of the 100-day ( $\sim 3$ months) running averages of solar wind velocity observed at IMP 8 (heliocentric distance $1 \mathrm{AU}$ ). Peaks roughly separated by $\sim 1.3 \mathrm{y}$ are marked with arrows and are seen more regularly in the recent cycle 22 

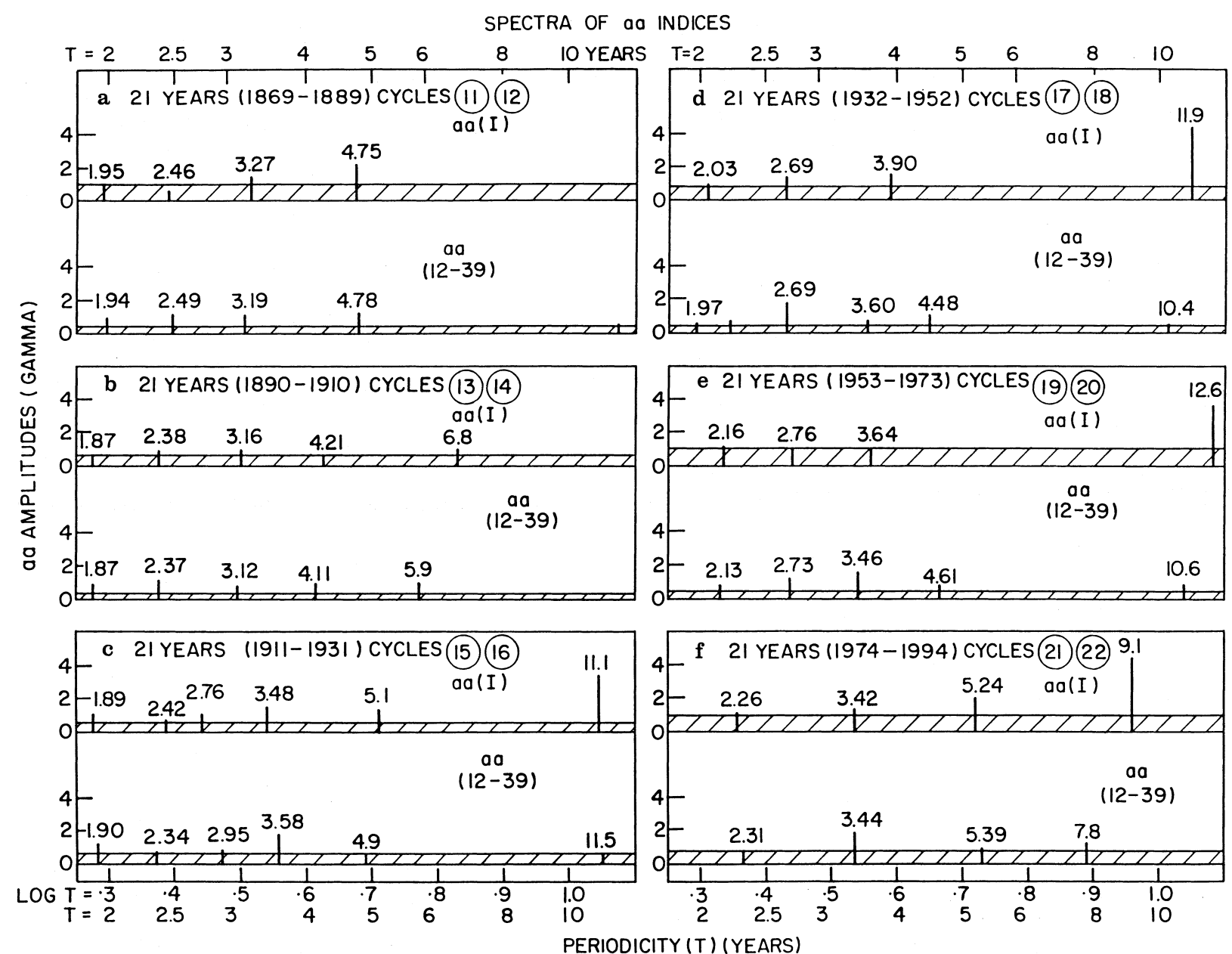

Fig. 5a-f. Spectra for aa(I) and aa (12-39) for consecutive 21 year intervals

(1985 onwards). The superposed thick line in Fig. 7a is a 12-monthly (4 season) running mean. Whereas the 1.3-y peaks have disappeared, other, larger-spaced peaks are now evident. Figure $7 \mathrm{~b}$ shows the 3-monthly means of aa index. Here, the 1.3 y peaks are seen in recent years, marked with arrows. Paularena et al. (1995) illustrated similar peaks in the Ap index for this interval.

Figure $7 \mathrm{c}$ shows the 12 -monthly (4 season) running means of the aa index. The 1.3 y peaks are eliminated; but fluctuations with larger periodicities are seen. Figure $7 d$ shows the 12-month running means (double smoothed) of sunspot numbers for cycles 20,21, 22, with maxima indicated by solid circles and minima by vertical lines. In cycles 20,21, the aa maxima (marked by squares) occurred 5 and 3 y after the sunspot maxima. But in cycle 22, the sunspot maximum was broad and aa had 3 maxima, two of which coincided with the broad sunspot maxima and the third occurred a few years later.

Figure 7e shows aa (12-39) i.e. 12-monthly minus 3year running means. When the aa index in Fig. 7c is corrected for direct solar cycle effect, the residual I component aa(I) is shown in Fig. 7f using our direct regression, and in Fig. $7 \mathrm{~g}$ using the equation given by Feynman (1982). Figure 8 shows the spectra. In Fig. 8a for solar wind and Fig. 8b for aa index, spectra of 3- monthly means show many peaks in the low periodicity range $(0.5-1.0 \mathrm{y})$ common to both. But most of these are barely significant and among these, only 1.3 y stands out with significance. It is not highly significant, because it is the average for 3 solar cycles and, as observed by Gazis et al. (1995), this periodicity was prominent only in cycle 22. In our Fig. 1 where analysis for the recent cycle (1984-1994) was illustrated, the 1.3 y peak was very prominent.

Figure 8c,d shows spectra for solar wind and aa index for 12-monthly running means. Here, all low periodicities are insignificant and only 3.6, 4.8 and $8.6 \mathrm{y}$ peaks are significant, in both solar wind and aa. Thus, all fluctuations in aa seem to be caused by similar fluctuations in the solar wind. In the parameters aa (1239) (Fig. 8e) and aa(I) (Fig. 8f), the same periodicities are depicted and, in addition, a periodicity near $1.94 \mathrm{y}$ of border-line significance is indicated.

Figure 9 shows the spectra for 3-monthly running means of solar wind and aa indices for sunspot cycles 20 , 21, 22 separately. In cycle 20, solar wind has barely significant peaks at 1.05 and $1.55 \mathrm{y}$ and a significant peak at $6.5 \mathrm{y}$. In aa, only $6.5 \mathrm{y}$ is significant. In cycle 21 , only $1.79 \mathrm{y}$ in solar wind and $4.0 \mathrm{y}$ in aa index are significant. In contrast, in cycle 22, the solar wind has $0.52 \mathrm{y}(\sim 6 \mathrm{~m})$ and aa index has $1.01 \mathrm{y}$ (annual) that are 


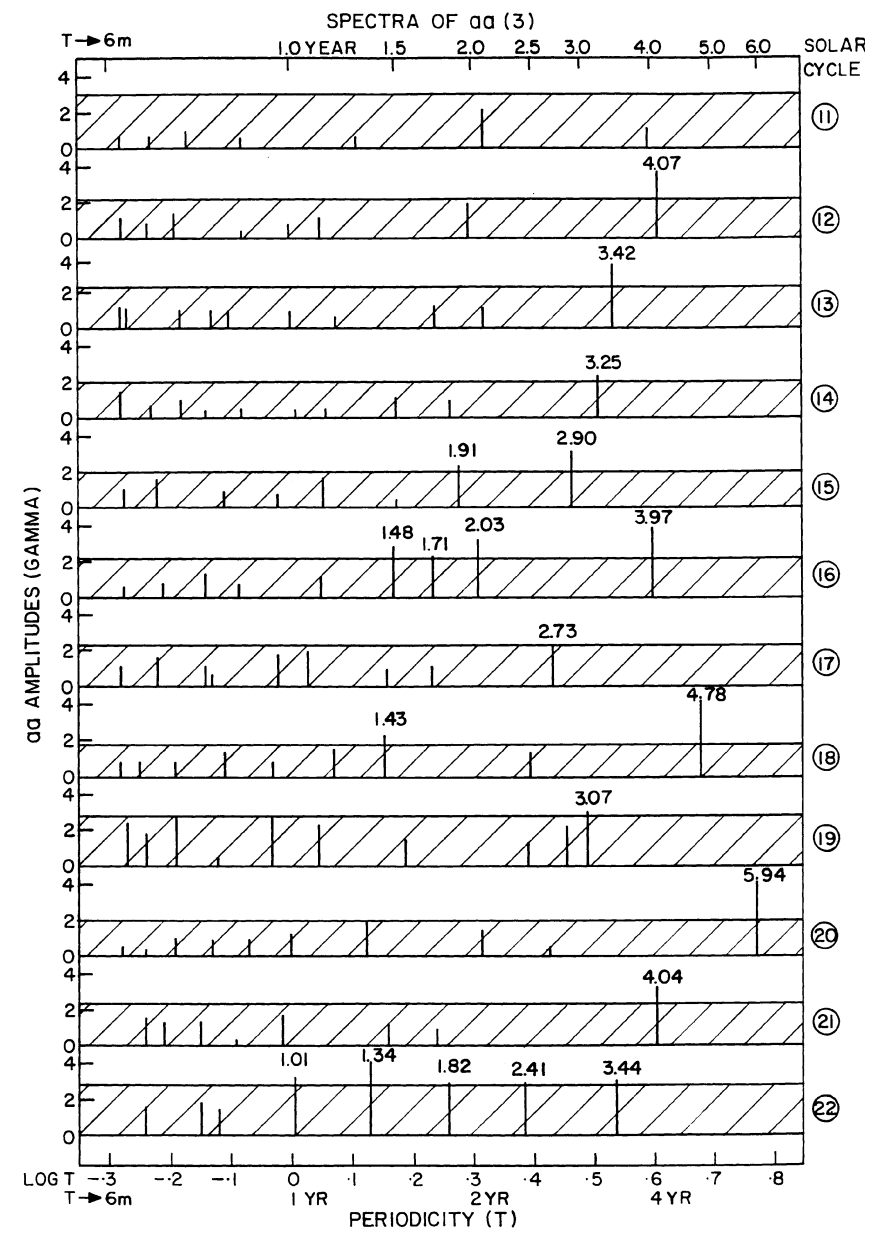

Fig. 6. Spectra for 3-monthly aa indices, (44 values in $11 \mathrm{y}$ ) separately for the solar cycles 11-22. The hatched portions represent $2 \sigma$ limits

significant, 1.28 in solar wind and $1.34 \mathrm{y}$ in aa index are highly significant, while 2.61 y (QBO) is significant only in solar wind case. Thus, significant fluctuations in both aa and solar wind (especially near $1.3 \mathrm{y}$ ) occurred only in cycle 22.

It would be interesting to check the correlations between the aa index and solar wind. Results of a crosscorrelation analysis are shown in Fig. 10. For the total period 1964-1995 (solar cycles 20, 21, 22), the maximum correlation was at zero lag and was $+0.61 \pm 0.06$ for the 3 -monthly means and $+0.65 \pm 0.06$ for the 12 -monthly means. Thus, the parallelism was by no means perfect. For individual cycles, the maximum correlation was at zero ( \pm 1 season i.e. \pm 3 months $)$ lag and was $+0.91 \pm 0.02$ for cycle $20,+0.77 \pm 0.04$ for cycle 21 and $+0.73 \pm 0.04$ for cycle 22 . Thus, the relationship between the solar wind and aa index was not equally strong for all three cycles, allowing for the possibility of some other interfering factors.

\section{Relationship with atmospheric parameters}

Several decades ago, a QBO was discovered in tropical stratospheric zonal winds (Reed et al., 1961; Veryard and Ebdon, 1961; Angell and Korshover, 1962). This QBO has systematic phase changes with altitude and latitude (Naujokat, 1986). The westerly accelerations appear first at the equator and spread with time to higher latitudes. The maximum occurs later at lower altitudes, by $10-12$ months from $10 \mathrm{mb}$ to $50 \mathrm{mb}$. The QBO is reflected in stratospheric temperatures and ozone (Angell and Korshover, 1962; Funk and Garnham, 1962) and there is some evidence that ionospheric parameters are also affected (Kane, 1995, 1996 and references therein). For lower altitudes, Yasunari (1989) indicated a possible link between stratospheric and tropospheric parameters. On the surface of the Earth, there is another well-known phenomenon viz. ENSO (El Nino/Southern Oscillation) which also exhibits QBO and QTO. Since stratospheric wind data are available only from $\sim 1951$ onwards, a comparison is possible only for the 4 solar cycles 19, 20, 21 and 22. Figure 11 shows the plots of 12-monthly (4 season) running means in two panels, the upper one for 1953-1975 and the lower one for 1976-1995. The first plot is for $50 \mathrm{hPa}$ zonal wind mostly at Singapore $\left(1^{\circ} \mathrm{N}, 104^{\circ} \mathrm{E}\right)$ (westerly positive, W; easterly negative, E; Pawson et al., 1993 and further private communication) and shows a striking QBO. The next plot is for the Southern Oscillation (SO) index represented by Tahiti (T) minus Darwin (D) mean sea-level pressure difference (T - D) (Parker, 1983, updated from Monthly Climate Data for the World published by National Climatic Data Center, Asheville, North Carolina, USA). The third plot is for equatorial eastern Pacific sea-surface temperature SST (Angell, 1981 and further private communication). The occurrence of El Ninos (Quinn et al., 1978, 1987) is shown by rectangles (solid, strong; hatched, moderate; open, weak), and coincides with $(\mathrm{T}-\mathrm{D})$ minima and SST maxima. The fourth plot is for aa (12-39).

Figure 12 shows the MESA spectra for these parameters. In the upper half (Fig. 12a) for 1953-1973 (sunspot cycles 19,20), the $50 \mathrm{hPa}$ wind has the most prominent peak at 2.38 y (QBO), two smaller peaks at 2.01 and $2.95 \mathrm{y}$, and a still smaller peak at $5.0 \mathrm{y}$. In contrast, $(\mathrm{T}-\mathrm{D})$ and SST, besides being similar to each other (both are a part of ENSO), have their major peaks at 3.58-3.73 y (QTO), a smaller peak at $\sim 2.85 \mathrm{y}$ (QBO), a barely significant peak at 2.16 y and at 7.4 years. Thus, $(\mathrm{T}-\mathrm{D})$ and SST have characteristics very different from those of the $50 \mathrm{hPa}$ zonal wind, except for a possible common link at $\sim 2.90$ y periodicity. The aa $(12-$ 39) shows significant peaks at 2.13, 2.73, 3.46 y. Since the accuracy of peak detection in MESA is $\sim 0.05 \mathrm{y}$ in this region, 2.13 may be considered as the same as 2.16; but 2.73 should be considered to be different from 2.85 , 2.88 or 2.95 , and 3.46 different from 3.58 or 3.73 . Thus, the aa index peaks are not quite the same as the $50 \mathrm{hPa}$ wind peaks or the $(\mathrm{T}-\mathrm{D})$, SST peaks.

The lower half (Fig. 12b) refers to 1974-1994 (sunspot cycles 21,22 ). Here, the $50 \mathrm{hPa}$ wind has one highly significant peak at $2.49 \mathrm{y}$, while $(\mathrm{T}-\mathrm{D})$, SST have the strongest peaks at $\sim 4.50 \mathrm{y}$, a smaller peak at $\sim 3.45 \mathrm{y}$ and still smaller peaks at $\sim 2.45 \mathrm{y}$ (similar to the $2.49 \mathrm{y}$ peak of the $50 \mathrm{hPa}$ wind). Thus again, $(\mathrm{T}-\mathrm{D})$, SST 


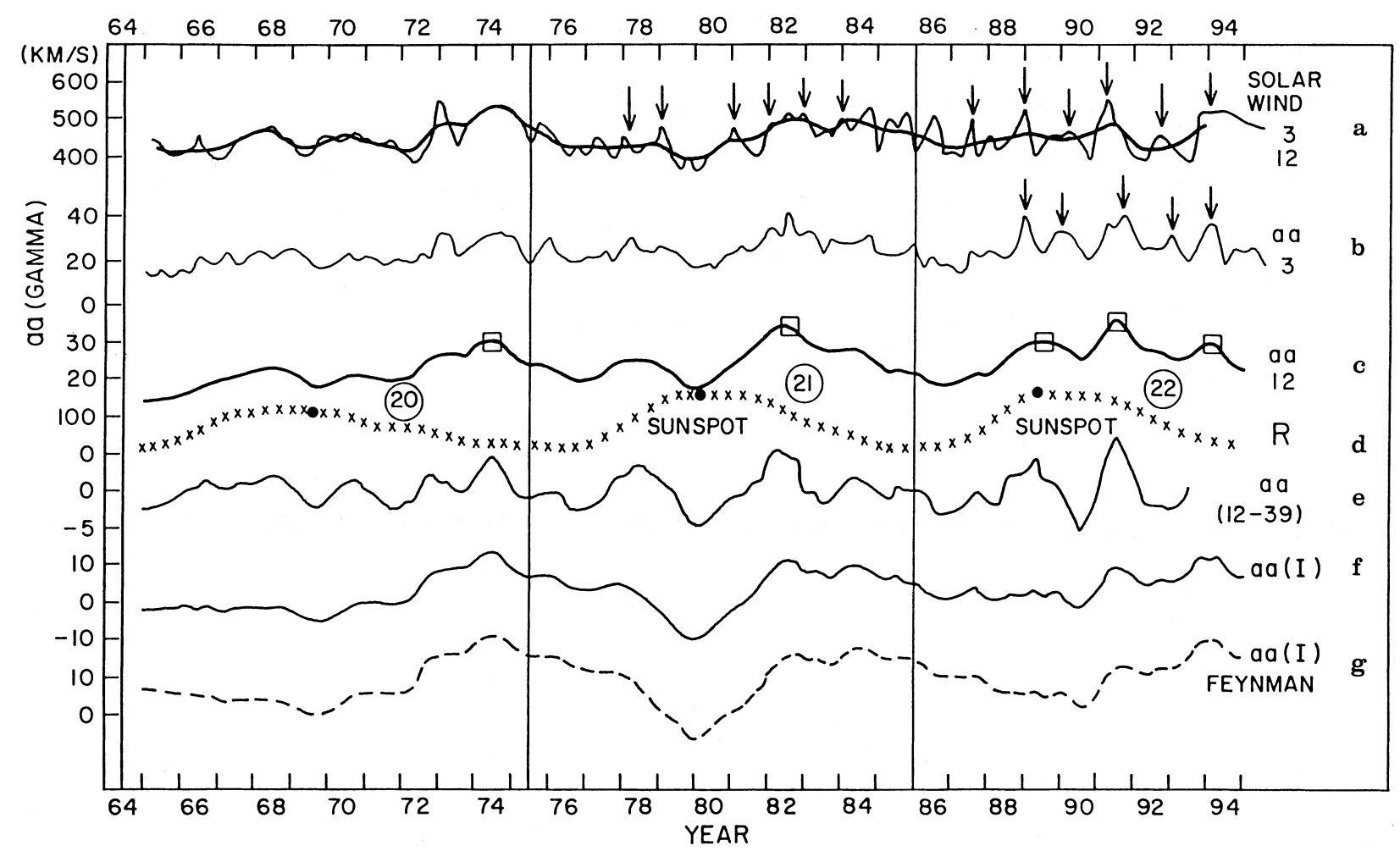

Fig. 7a-g. Plots for 1964-1994, a solar wind at IMP 8, 3-monthly means (thin lines) and 12-monthly means (superposed thick line), $\mathbf{b}$ aa indices 3-monthly means. The arrows in a,b indicate 1.3 year peaks, $\mathbf{c}$ aa indices 12-monthly means, $\mathbf{d}$ smoothed sunspot numbers (crosses), e aa (12-39), f,g aa(I) using sunspot regression of present analysis and of Feynman

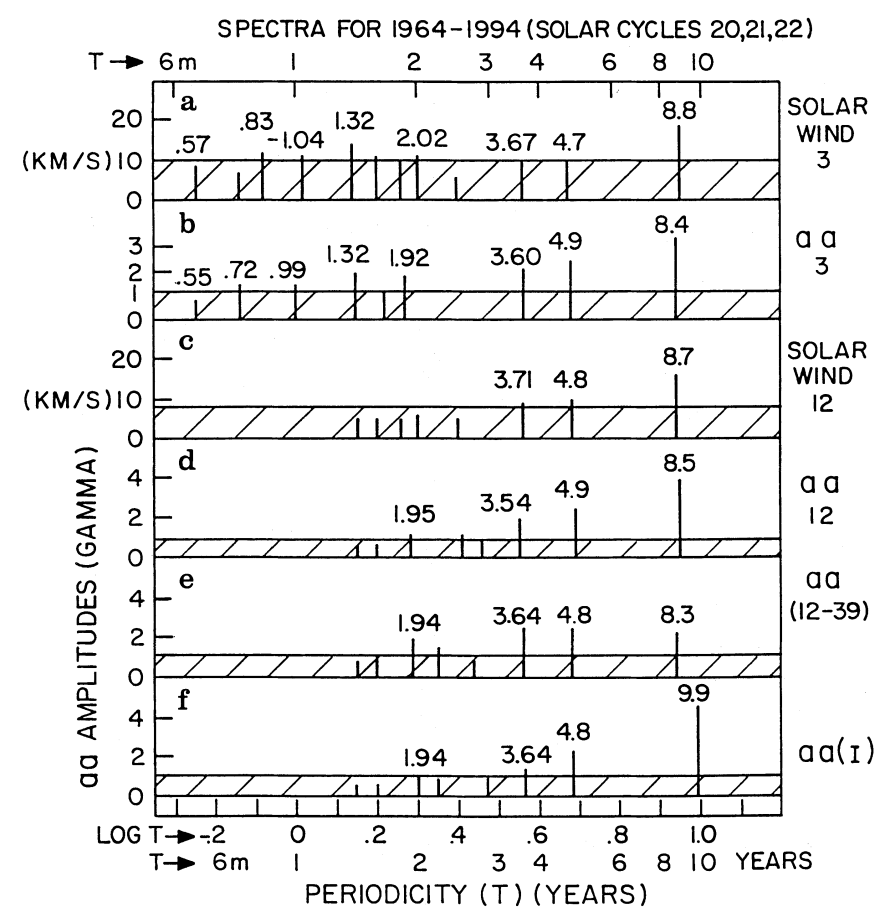

Fig. 8a-f. Spectra for a,b 3-monthly means and c,d 12-monthly means of solar wind and aa indices for 32-y period 1964-1995 (solar cycles $20,21,22)$, e aa (12-39) and $\mathbf{f}$ aa(I)

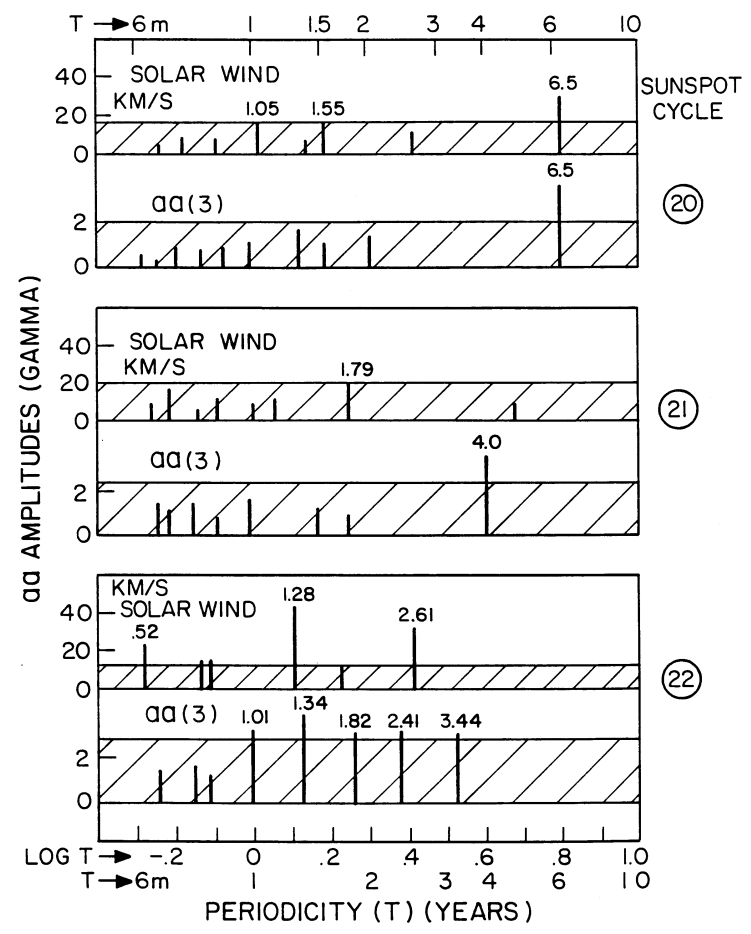

Fig. 9. Spectra for 3-monthly means of solar wind and aa indices for cycles $20,21,22$ separately 


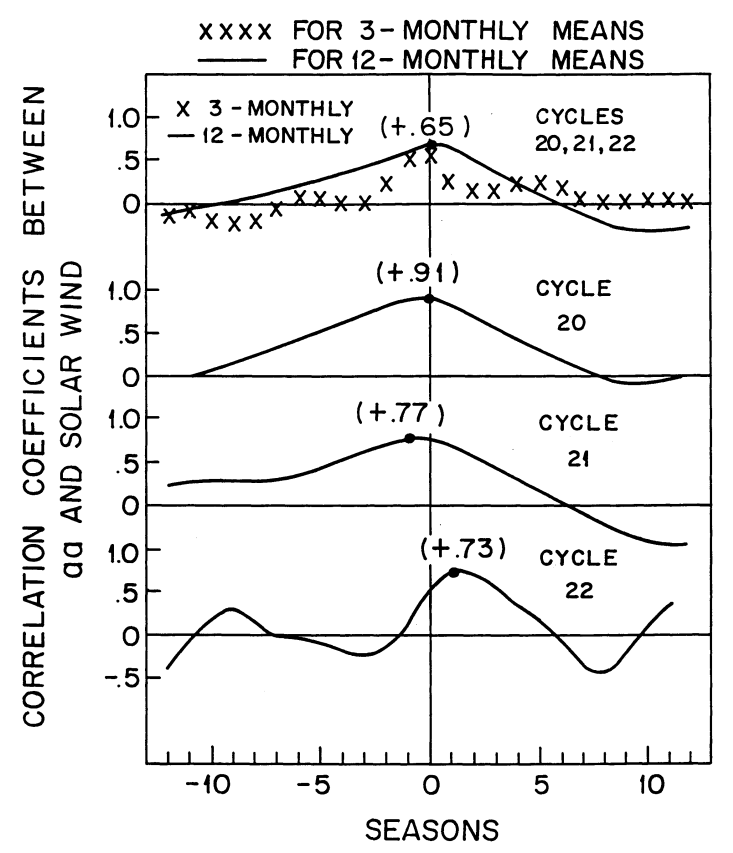

Fig. 10. Cross-correlations between solar wind and aa indices. Crosses, 3-monthly values; solid lines, 12-monthly values

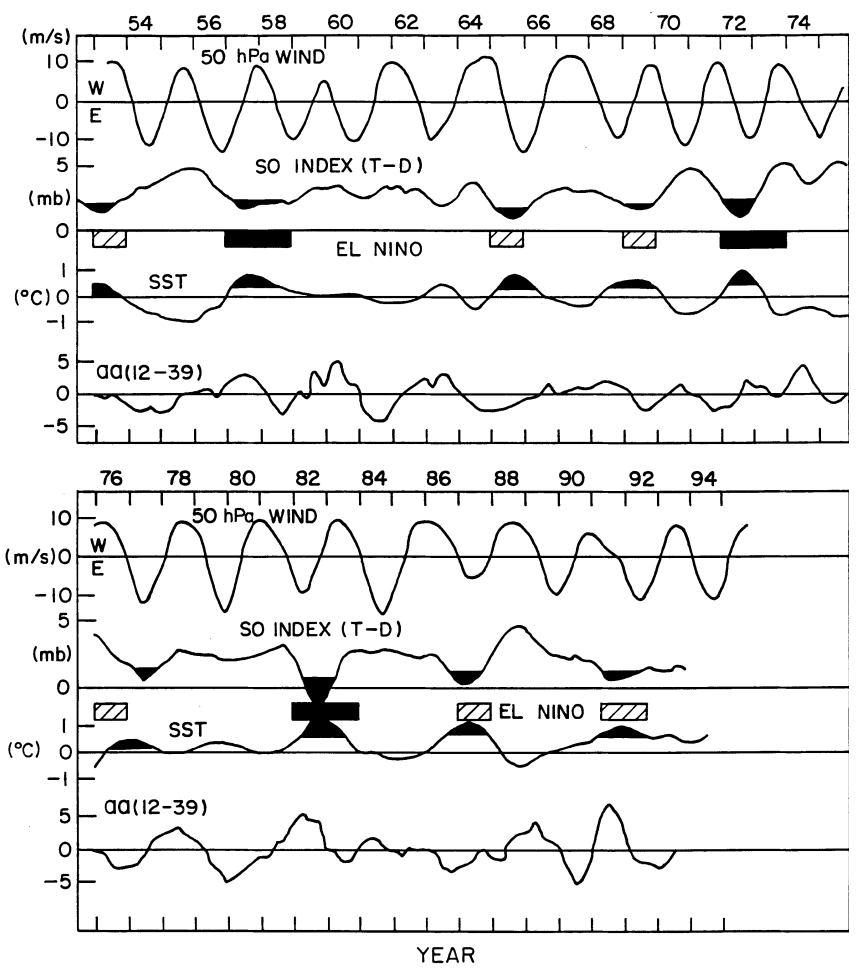

Fig. 11. The 12-monthly running of $50 \mathrm{hPa}$ wind, Southern Oscillation $(S O)$ index $(T-D)$, equatorial eastern Pacific sea-surface temperature SST and aa (12-39), for 1953-1975 in the upper panel and 1976-1995 in the lower panel. Minima of $(T-D)$ and maxima of SST are shown black and coincide with El Nino events shown by rectangles $($ solid $=$ strong; hatched $=$ moderate; blank $=$ weak $)$

have characteristics very similar to each other but different from those of the $50 \mathrm{hPa}$ wind, except for a possible link at $\sim 2.45 \mathrm{y}$ peak. The aa (12-39) has a

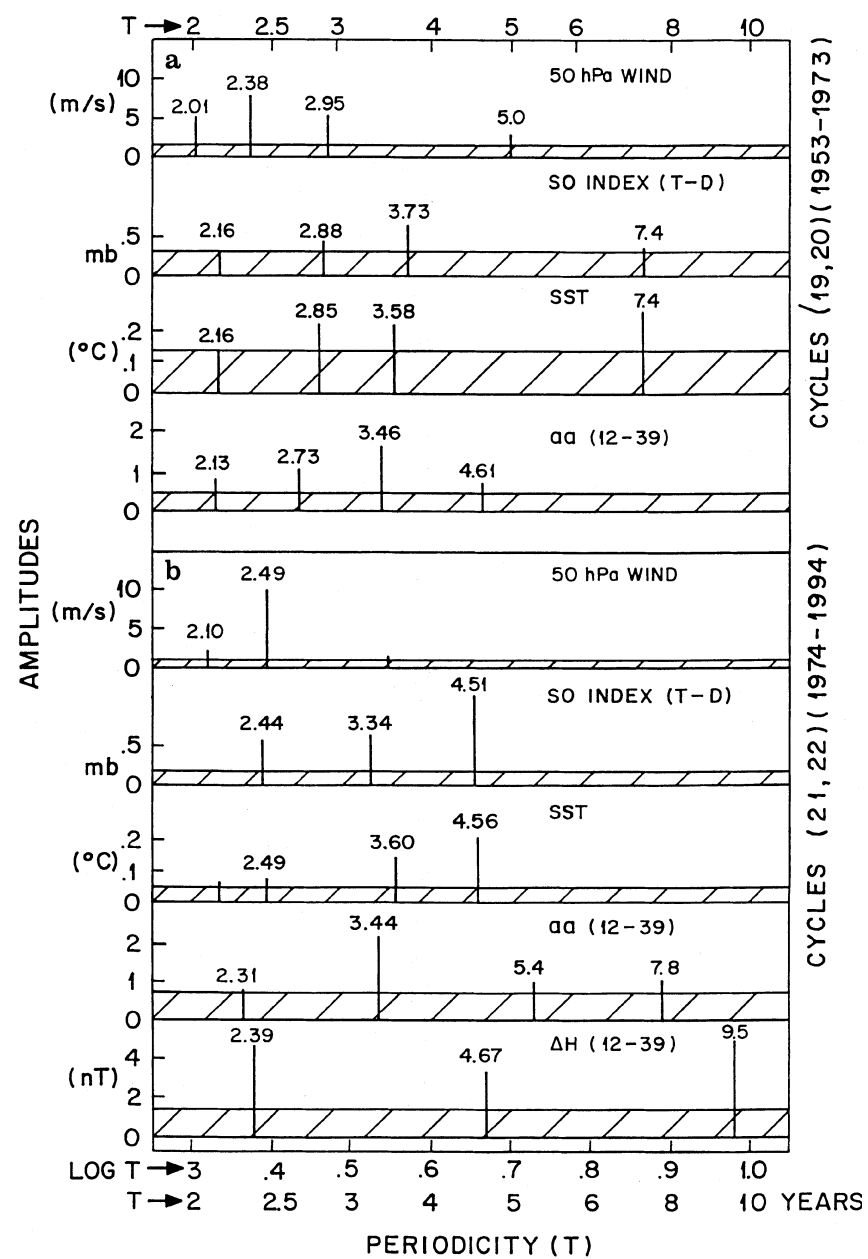

Fig. 12a,b. Spectra of the 12-monthly running mean series of $50 \mathrm{hPa}$ wind, SO index (T-D), SST and aa (12-39) for two consecutive 21year intervals a 1953-1973 (cycles 19, 20, upper panel) and b 19741994 (cycles 21, 22, lower panel). Here, $\Delta H$ (12-39) is also shown, representing quiet day daily range of the geomagnetic $H$ component at Trivandrum (equator, India)

prominent peak at $3.44 \mathrm{y}$, which may be considered as matching with $3.34-3.60 \mathrm{y}$ peaks of $(\mathrm{T}-\mathrm{D})$, SST. Considering both the intervals viz. cycles 19, 20 and 21,22 , the aa (12-39) seems to match (T - D), SST at $\sim 3.50 \mathrm{y}$ and has no match with the $50 \mathrm{hPa}$ wind. Incidentally, the quiet-day daily range of the $\mathrm{H}$ component of geomagnetic field at low latitudes has a QBO (Kane, 1996 and references therein). For 1972-1990 (solar cycles 21, 22), the spectra for Trivandrum in the equatorial electrojet region of India are shown as the bottom plot of Fig. 12b and show a prominent peak at $2.39 \mathrm{y}$, not very different from the 2.49 y peak of $50 \mathrm{mb}$ wind, thus indicating some relationship between the two. However, there is a significant peak at $4.67 \mathrm{y}$ also, not very different from the 4.51 and $4.56 \mathrm{y}$ peaks of (T - D), SST. Thus, the quiet-day $\mathrm{H}$ component daily range seems to be related with both stratospheric winds as well as ENSO, while aa seems to be probably related to ENSO only.

This result is very strange indeed. It seems unimaginable that a terrestrial feature like ENSO should affect 
geomagnetic disturbances, which are mostly related to solar wind. On the other hand, Perez-Enriquez et al. (1989) and Mendoza et al. (1991) report a curious finding that $\sim 63 \%$ of the ENSO episodes occurred during the descending phases of the sunspot cycle. This needs further exploration.

Since the stratospheric wind and ENSO characteristics changed substantially from cycles 19,20 to cycles 21 , 22, a spectral analysis was carried out for still smaller intervals. The 42-y interval 1953-1994 was divided into three intervals of $14 \mathrm{y}$ each and the spectra are shown in Fig. 13. In the first interval 1953-1966 (Fig. 13a), the $50 \mathrm{hPa}$ wind had the most prominent peak at $2.20 \mathrm{y}$ and a smaller peak at $3.07 \mathrm{y}$. The $(\mathrm{T}-\mathrm{D})$, SST had prominent peaks at $\sim 7.0,4.5,2.80$ and $2.05 \mathrm{y}$, very
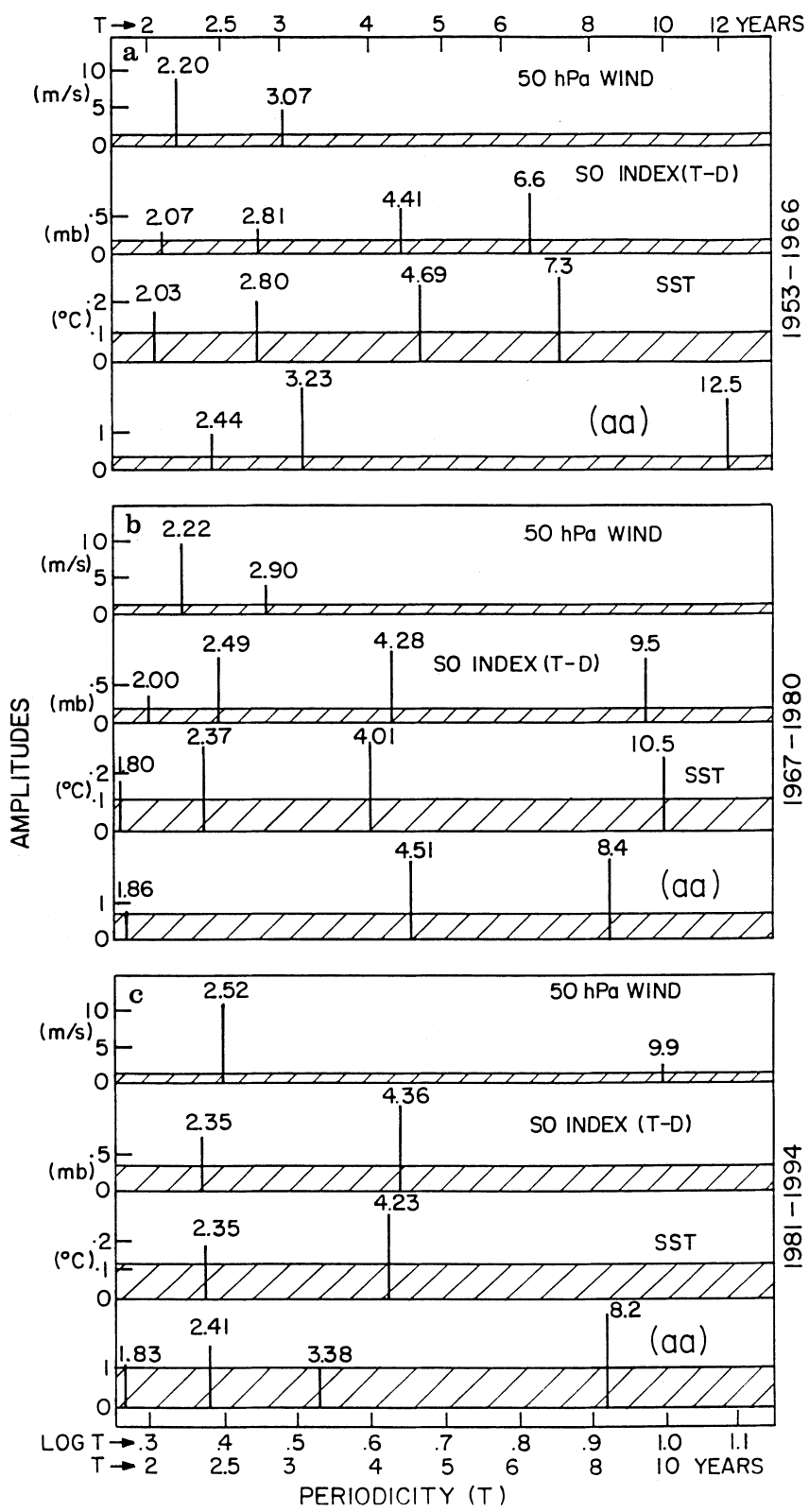

Fig. 13a-c. Spectra of the 12-monthly running mean series of $50 \mathrm{mb}$ wind, SO index (T-D), SST and $a a$ (12-39) for three consecutive 14year intervals a 1953-1966, b 1967-1980, c 1981-1994 different from those of the $50 \mathrm{mb}$ wind. The aa index had peaks at 2.44 and $3.23 \mathrm{y}$, very different from those of $50 \mathrm{hPa}$ wind or ENSO.

Figure 13b shows spectra for 1967-1980. Here, $50 \mathrm{hPa}$ wind had a prominent peak at $2.22 \mathrm{y}$ and a smaller peak at $2.90 \mathrm{y}$, not very different from those (2.20 and $3.07 \mathrm{y})$ of the earlier 14-y interval. But $(\mathrm{T}-\mathrm{D})$, SST had prominent peaks at $\sim 10,4.10$ and $2.40 \mathrm{y}$, different from those of the earlier interval and from those of the $50 \mathrm{hPa}$ wind. The aa index had a prominent peak at $4.51 \mathrm{y}$, different from the ENSO peaks.

Figure 13c refers to $1981-1994$. Here, the $50 \mathrm{hPa}$ wind had one prominent peak at $2.52 \mathrm{y}$, very different from those of the earlier two intervals (2.20 and $2.22 \mathrm{y})$. The $(\mathrm{T}-\mathrm{D})$, SST had prominent peaks at (4.23-4.36) y, in-between the peaks (4.41-4.69) y of the first interval and (4.01-4.28) y of the second interval, and also a smaller peak at $2.35 \mathrm{y}$. The aa index had a prominent peak at $2.41 \mathrm{y}$, more like the $2.35 \mathrm{y}$ of ENSO than $2.52 \mathrm{y}$ of $50 \mathrm{hPa}$ wind.

Overall, whereas the aa indices did have peaks in the QBO and QTO regions, these did not match with the QBO of $50 \mathrm{hPa}$ wind and only sometimes matched with ENSO peaks. A cross-correlation analysis between aa indices and $50 \mathrm{hPa}$ wind or $(\mathrm{T}-\mathrm{D})$ or $\mathrm{SST}$ gave correlation coefficients never exceeding 0.40 , for any lag or lead.

\section{Conclusions and discussion}

Figure 14 is a quick-look plot for the whole period 1868-1995. The top plot is for 12-month running means (double smoothed) of sunspots, where the maxima are indicated by dots and vertical dashed lines and the minima by vertical solid lines. The second plot is for 12monthly running means of aa index, as in Fig. 1 but centered 6 months apart (two values per year) and the aa maxima are indicated by squares. The third plot is for the 3-y running means of aa index and the fourth plot is for the residues aa (12-39) i.e. the difference of the second and the third plots. From these plots and those of the earlier figures, the following conclusions can be drawn:

1. The various solar cycles differ considerably from each other. The solar minimum may be short $(\sim 1 \mathrm{y})$ or long $(\sim 2-3 y)$. The maximum also may be short $(\sim 1 \mathrm{y})$ or long $(\sim 2-3 \mathrm{y})$. The maximum sunspot number decreased from cycle 11 to cycle 14, increased thereafter up to cycle 19 (1957-1958, IGY), decreased considerably in cycle 20 , and rose to moderate levels in cycles 21,22 . Indications of long-term periodicities (50-100 years etc.) are discussed by Feynman (1982).

2. Whereas the aa index minima do occur at or near (within 1-2 y of) the sunspot minima (low geomagnetic activity during sunspot minimum), the aa maxima have an irregular pattern. Generally, two aa maxima are observed (double-peaked modulation). The major aa peak is reported as occurring during the declining phase of the sunspot cycle and a 


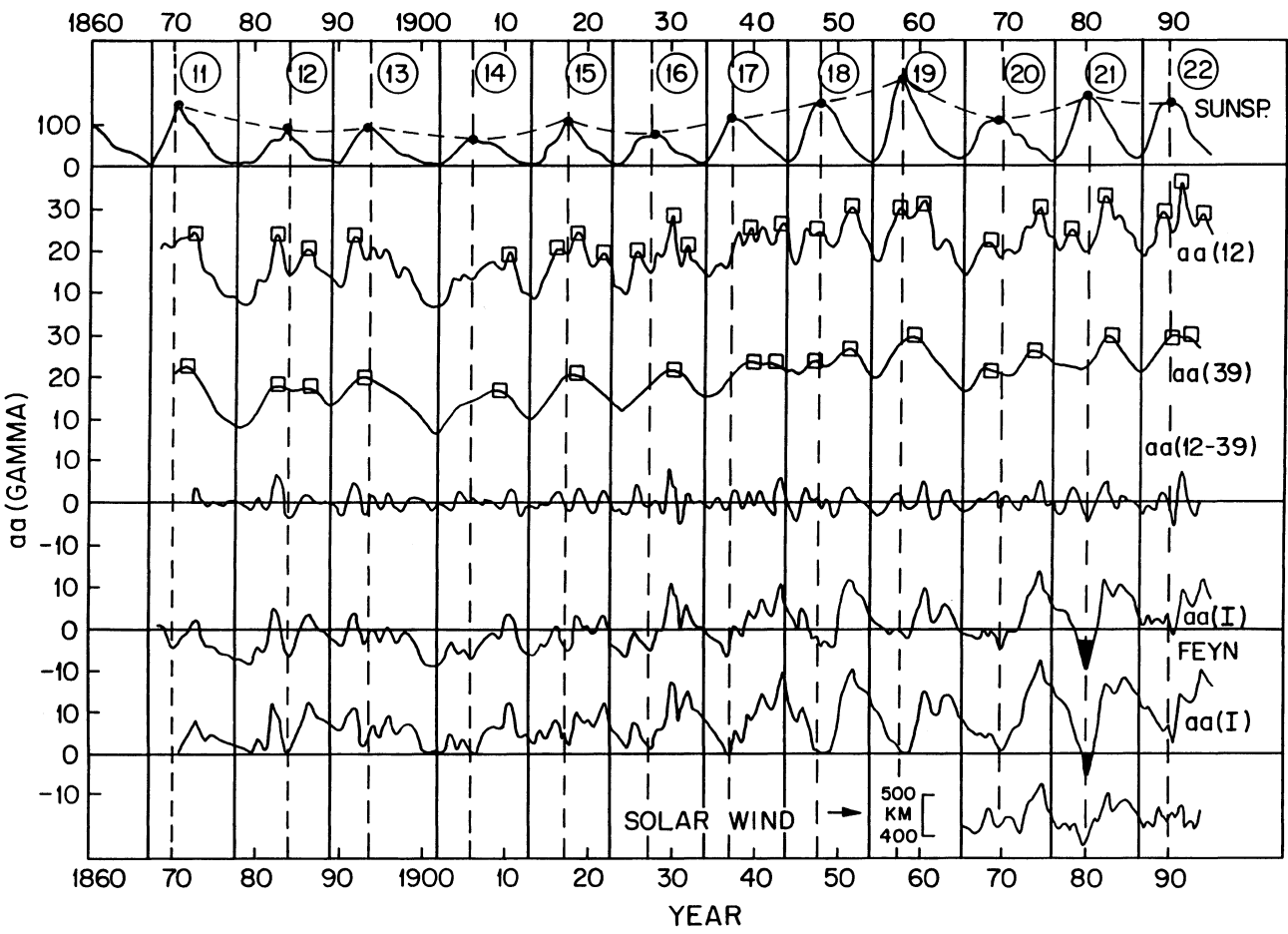

Fig. 14. Plots of sunspot numbers, $a a(12), a a(39), a a(12-39)$ and two $a a(I)$ (present analysis and Feynman) for 1868-1995 (128 years, cycles 11-22) and for solar wind at IMP 8 for 19651994 secondary peak occurring near the sunspot maximum (Newton, 1948; Ohl, 1971; Gosling et al., 1977; Gorney, 1990). From Fig. 14, this seems to be generally true. However, for cycles 12, 13, the first aa peak was larger. In cycle 13 , there was only one aa peak, slightly before the sunspot maximum while in cycle 14 also, there was only one peak but in the declining phase. In some cycles, there were three peaks, the first one at or before the sunspot maximum and the other two in the declining phase. The first peak is termed by Feynman (1982) as the R component of aa index and is attributed to short-lived solar events such as solar flares, coronal transients, temporary coronal holes etc. If their effect is removed by using regression equations between aa index and sunspots, the residues aa(I) are shown in Fig. 14 as the fifth plot (our regression) and sixth plot (Feynman's regression). These are very similar to each other and resemble the aa (12-39) shown in the fourth plot in Fig. 14, except in intervals when the first aa peak was much earlier than the sunspot maximum and, more important, the aa value at sunspot maximum was very low, and hence, the regression caused over-correction, as in 1980 (shown black).

3. When the series are subjected to spectral analysis, the two-peaked and three-peaked structures of aa index result in QBO and/or QTO. These features are not present in all phases of the sunspot cycle. For example, during the end part of the declining phase and the early part of the rising phase (within 1-2 y of the sunspot minimum), the aa changes are negligible and the plots are smooth. Only the portion from 2 3 y before the sunspot maximum to $4-5$ y after the sunspot maximum has the QBO, QTO features. Since the peak structures differ from cycle to cycle, so do the QBO, QTO characteristics, from cycle to cycle. When the 126-y aa index data were divided into 6 intervals of $21 \mathrm{y}$ each, all intervals showed significant $\mathrm{QBO}$ at $\sim 2.00,2.15,2.40,2.70 \mathrm{y}$ and $\mathrm{QTO}$ at $\sim 3.20$, $3.40 \mathrm{y}$, but not all of these in all intervals. The aa(I) component is attributed to slowly varying solar events such as long-lived coronal holes (Feynman, 1982), which give recurring solar wind streams. Sargent (1979) calculated the correlation of each 27day (solar rotation period) time series of aa index with the next 27-day series and evolved a "recurrence index". Feynman (1982) compared this index with the ratio aa(I)/aa and found a good match, thus confirming that aa(I) does represent the slowly varying component of solar wind. The evolution of this I component during the declining phase of the sunspot cycle seems to differ considerably from cycle to cycle.

4. Direct comparison of aa variations with solar wind was possible only for 1965 onwards (solar cycles 20, 21, 22). The seventh plot in Fig. 14 is for solar wind. For the whole period, significant periodicities at 3.6, $4.8,8.6$ y were found in aa indices as well as in solar wind observed at IMP 9 (heliocentric distance $\sim 1 \mathrm{AU})$, thus confirming the intimate relationship between solar wind and geomagnetic activity. However, when series for the cycles 20, 21, 22 were compared separately, the correlation between aa and solar wind was 0.91 for cycle 20 , but only $\sim 0.75$ for cycles 21 and 22 . Thus, the parallelism is not always perfect, though a significant periodicity of $1.3 \mathrm{y}$ was noticed in both during cycle 22 only.

All these periodicities exist in the solar wind in the declining phase of sunspot activity. Their existence must be related to some processes in the Sun and needs further investigation. Gnevyshev (1967) showed 
a double-peak distribution in the intensity of some coronal processes. Gonzalez et al. (1987) reported 1.5 and $3.7 \mathrm{y}$ periodicities in IMF polarity, which must have their origins in the physical processes in the Sun.

5. Two atmospheric phenomena having strong QBO and/or QTO are, stratospheric low latitude zonal winds (mainly QBO) and, ENSO (El Nino/Southern Oscillation, mainly QTO). These were compared with aa variability for 1953 onwards (solar cycles 19, 20, $21,22)$. The spectral peaks of a index did not tally with those of $50 \mathrm{hPa}$ wind, but sometimes matched the $\sim 3.5 \mathrm{y}$ peaks of ENSO. This may or may not be a chance coincidence. Off hand, one does not see a plausible mechanism which could connect surface phenomena like ENSO with ionospheric and magnetospheric current systems, which cause geomagnetic changes. On the other hand, about $63 \%$ of ENSO events seem to have occurred during the declining phase of sunspot activity. This needs further exploration.

Acknowledgements. This work was partially supported by FNDCT, Brazil, under contract FINEP 573/CT.

Topical Editor K.-H. Glaßmeier thanks a Referee for his help in evaluating this paper.

\section{References}

Angell, J. K., Comparison of variations in atmospheric quantities with sea surface temperature variations in the equatorial eastern Pacific, Mon. Weath. Rev., 109, 230-243, 1981.

Angell, J. K., and J. Korshover, The biennial wind and temperature oscillations of the equatorial stratosphere and their possible extension to higher latitudes, Mon. Weath. Rev., 90, 122-132, 1962.

Bartels, J., Discussion of time variations of geomagnetic activity indices Kp and Ap 1932-1961, Ann. Geophysicae, 19, 1-20, 1963.

Bevington, P. R., Data reduction and Error Analysis for the Physical Sciences, McGraw-Hill, New York, pp. 164-176, 1969.

Blackman, R. B., and J. W. Tukey, The measurements of power spectra, Dover, New York, pp. 190, 1958.

Burg, J. P., Maximum Entropy Spectral Analysis, Paper presented at the 37th Meeting, Society of Exploration Geophysics, Oklahoma City, October, 1967.

Chen, W. Y., and G. R. Stegen, Experiments with maximum entropy power spectra of sinusides, J. Geophys. Res., 79, 30193022, 1974.

Currie, R. G., Long period magnetic activity -2 to 100 years, Astrophys. Space Sci., 39, 251-254, 1976.

Delouis, H., and P. N. Mayaud, Spectral analysis of the geomagnetic activity index aa over a 103-year interval, J. Geophys. Res., 80, 4681-4688, 1975.

Feynman, J., Geomagnetic and solar wind cycles 1900-1975, J. Geophys. Res., 87, 6153-6163, 1982.

Fraser-Smith, A. C., Spectrum of the geomagnetic activity index Ap, J. Geophys. Res., 77, 4209-4220, 1972.

Funk, J. P., and G. L. Garnham, Australian ozone observations and a suggested 24-month cycle, Tellus, 14, 378-382, 1962.

Gazis, P. R., J. D. Richardson, and K. I. Paularena, Long term periodicity in solar wind velocity during the last three solar cycles, Geophys. Res. Lett., 22, 1165-1168, 1995.

Gnevyshev, M. N., On the 11-years cycle of solar activity, Solar Phys., 1, 109-120, 1967.

Gonzalez, A. L. C., and W. D. Gonzalez, Periodicities in the interplanetary magnetic field polarity, J. Geophys. Res., 92, 43574375,1987
Gonzalez, W. D., A. L. C. Gonzalez, and B. T. Tsurutani, Dual peak cycle distribution of intense geomagnetic storms, Planet. Space Sci., 38, 181-187, 1990.

Gonzalez, A. L. C., W. D. Gonzalez, S. L. G. Dutra and B. T. Tsurutani, Periodic variations in the geomagnetic activity: a study based on the Ap index, J. Geophys. Res., 98, 9215-9231, 1993.

Gonzalez, W. D., B. T. Tsurutani, P. S. McIntosh, and A. L. C. Gonzalez, Coronal hole-Active region-Current Sheet (CHARCS) association with intense interplanetary and geomagnetic activity, Geophys. Res. Lett., 23, 2577-2580, 1996.

Gorney, D. J., Solar cycle effect on the near earth space environment, Rev. Geophys., 28, 315-336, 1990.

Gosling, J. T., J. R. Asbridge, S. J. Bame and W. C. Feldman, Solar wind speed variations: 1962-1974, J. Geophys. Res., 81, 50615070, 1976.

Gosling, J. T., J. R. Asbridge and S. J. Bame, An unusual aspect of solar wind speed variations during solar cycle 20, J. Geophys. Res., 82, 3311-14, 1977.

Kane, R. P., Power spectrum analysis of solar and geophysical parameters, J. Geomag. Geoelect., 29, 471-495, 1977.

Kane, R. P., Maximum entropy spectral analysis of some artificial samples, J. Geophys. Res., 84, 965-966, 1979.

Kane, R. P., Power spectrum analysis of geomagnetic activity indices, Proc. Indian Acad. Sci. (Earth and Planet. Sci.), 95, 112, 1986.

Kane, R. P., Quasi-biennial oscillation in ionospheric parameters measured at Juliusruh $\left(55^{\circ} \mathrm{N}, 13^{\circ} \mathrm{E}\right), \mathrm{J}$. Atmos. Terr. Phys., 57, 415-419, 1995.

Kane, R. P., Quasi-biennial oscillations in quiet-day ranges of low latitude geomagnetic $\mathrm{H}$ component, Indian J. Radio \& Space Phys., 25, 101-105, 1996.

Kane, R. P., and N. B. Trivedi, Comparison of Maximum Entropy Spectral Analysis (MESA) and Least-Squares Linear Prediction (LSLP) methods for some artificial samples, Geophysics, 47, 1731-1736, 1982.

Lacoss, R. T., Data adaptive spectral analysis methods, Geophysics, 36, 661-675, 1971.

Legrand, J. P., and P. A. Simon, Solar cycle and geomagnetic activity: a review for geophysicists Part I: the contributions to geomagnetic activity of shock waves and of solar wind, Ann. Geophysicae, 7, 565-578, 1989.

Mayaud, P. N., A hundred year series of geomagnetic data 1868 1967, indices aa, storm sudden commencements, IAGA Bull., 33, pp 262, 1973.

McKinnon, J. A., Sunspot numbers: 1610-1985, Report UAG95, WDC-A for Solar-Terrestrial Physics, National Academy of Sciences, Washington DC, USA, January 1987, pp. 112.

Mendoza, B., R. Perez-Enriquez, and M. Alvarez-Madrigal, Analysis of solar activity conditions during periods of El Nino events, Ann. Geophysicae, 9, 50-54, 1991.

Naujokat, B., An update of the observed quasi-biennial oscillation of the stratospheric winds over the tropics, J. Atmos. Sci., 43, 1873-1877, 1986.

Newton, H. W., Sudden commencements in the Greenwich magnetic records (1879-1944) and related sunspot data, Mon. Not. R. Astron. Soc. Geophysi. Suppl., 5, 159-185, 1948.

Ohl, A. I., Physics of the 11 year variation of geomagnetic disturbances, Geomagn. Aeron., 11, 549-550, 1971.

Parker, D. E., Documentation of a Southern Oscillation index, Meteorol. Mag., 112, 184-188, 1983.

Paularena, K. I., A. Szabo and J. D. Richardson, Coincident 1.3 year periodicities in the Ap geomagnetic index and the solar wind, Geophys. Res. Lett., 22, 3001-3004, 1995.

Pawson, S., K. Labitzke, R. Lenschow, B. Naujokat, B. Rajewski, M. Wiesner and R.-N. Wohlfart, Climatology of the Northern Hemisphere stratosphere derived from Berlin Analyses - Part 1: monthly means, Meteorologische Abhandlungen des Instituts fur Meteorologie der Freien Universitat Berlin, Neue Folge Serie A Monographien Band 7/Heft 3, 1993. 
Perez-Enriquez, R., B. Mendoza and M. Alvarez-Madrigal, Solar activity and El Nino: the auroral connection, Il Nuovo. Cim., 12C, 223-230, 1989.

Quinn, W. H., D. O. Zopf, K. S. Short and R. T. W. Kuo Yang, Historical trends and statistics of the Southern Oscillation, El Nino and Indonesian droughts, Fish. Bull., 76, 663-678, 1978.

Quinn, W. H., V. T. Neal and S. E. Antunez de Mayolo, El Nino occurrences over the past four and a half centuries, J. Geophys. Res., 92, 14449-14461, 1987.

Rangarajan, G. K., Quasibiennial oscillation in geomagnetic disturbance field, Proc. Indian Acad. Sci. (Earth and Planet. Sci.), 94, 29-34, 1985.

Reed, R. J., W. J. Campbell, L. A. Rasmusson, and D. J. Rogers, Evidence of a downward propagating annual wind reversal in the equatorial stratosphere, J. Geophys. Res., 66, 813-818, 1961.

Richardson, J. D., K. I. Paularena, J. W. Belcher and A. J. Lazarus, Solar wind oscillations with a 1.3 year period, Geophys. Res. Lett., 21, 1559-1560, 1994.
Rogova, O. G., and L. K. Shatashvili, Quasiperiodic 2-year variation in cosmic rays, solar activity, solar wind and geomagnetic activity, Geomag. Aeron., 30, 482-484, 1990.

Sargent, H. H., A 27-day geomagnetic reccurence index 1868-1978, in Solar-Terr. Phys. and Meteorol. Working Document III. World Data Center A, Boulder, Colorado, 1979.

Sugiura, M., and D. J. Poros, Solar-generated quasi-biennial geomagnetic variation, J. Geophys. Res., 82, 5621-5628, 1977.

Szabo, A., R. P. Lepping and J. H. King, Magnetic field observations of the 1.3 year solar wind oscillation, Geophys. Res. Lett., 22, 1845-1848, 1995.

Ulrych T. J., and T. N. Bishop, Maximum entropy spectral analysis and autoregressive decomposition, Rev. Geophys., 13, 183-200, 1975.

Veryard, R. G., and R. A. Ebdon, Fluctuations in tropical stratospheric winds, Meteorol Mag., 90, 125-143, 1961.

Yasunari, T., A possible link of the QBOs between the stratosphere, troposphere and the surface temperature in the tropics, $J$. Meteorol. Soc. Japan, 67, 483-493, 1989. 